\title{
TOWARDS A POST COVID-19 DIGITAL AUTHENTIC ASSESSMENT PRACTICE: WHEN RADICAL CHANGES ENHANCE THE STUDENT EXPERIENCE
}

\author{
Stylianos Hatzipanagos, Alan Tait, Linda Amrane-Cooper, Centre for Distance Education, \\ University of London, United Kingdom
}

\section{Abstract}

In 2020, the Higher Education sector, in the UK and internationally, had to move to online assessment because of the Covid-19 pandemic, at a speed and scale which might have been unimaginable under normal circumstances. By upscaling and accelerating the adoption of digital assessment practices in distance and online education across the world, educators had to rethink assessment processes to make sure they were an integral part of the authentic digital life experience for students and staff.

As these changes appear to be far from temporary, they have accelerated the transition to a "new normal" regime of assessing students online for the foreseeable future. The priority in the sector is that fundamental principles of assessment including integrity and authenticity are supported in the design and implementation of assessments. In addition ensuring that no student is disadvantaged in accessing digital learning opportunities, when they are assessed.

The paper discusses a project that collected data about three final assessment routes students have taken. The aim was to generate understanding of this transition to online assessment, primarily from the perspective of the experience of the students who have been affected.

Our findings explore student agreement with this transition to online assessment and provide an opportunity to understand student approaches to assessment and what they would like to see in future assessments. Finally we explore the implications for practice in distance learning and campus based environments and for the sector.

Keywords: Online assessment, e-assessment, transition to online learning, online exams, student experience. 


\section{Introduction}

After the onset of the coronavirus, universities all over the world had to move their operations to online spaces. This has also affected assessment practices, particularly when the locus was on campus or at teaching centres. The University of London Worldwide students had to move to online assessment in place of conventional examinations in exam halls during the Covid-19 pandemic, which precluded such events. Approx. 110,000 exams events were impacted by closure of exam centres around the world.

Such an abrupt transition to online assessment, posed instantly important questions about the quality of the student experience (equivalent to, or "as good as" the previous set-up) of the transition. Covid-related transitions had a catalytic effect on assessment philosophies and strategies and discussions about the right timing of transitioning. They also posed three related questions: (a) What measures would institutions need to put in place to ensure that the student experience of assessment was positive and unaffected by technology, format, or location, until institutions went back to normal? (b) What was the impact of transitions on pedagogy of assessing student performance? and (c) Was it the right time (taking evaluations into account) to move to online assessment practices for the longer term?

The paper focuses on a project that collected data about such a transition, whose aim was to generate understanding of the transition to online assessment, primarily from the perspective of the experience of the students who were affected.

\section{Assessment theories and online assessment in practice}

Recent debates on assessment in the higher education sector revolve around changes and uncertainty for the future, mainly investigating whether 2020 has marked the beginning of the end for in-person, fixed-time, paper-based assessment (JISC, 2020a; Emerge Education \& JISC 2020). In addition, universities see a need for balance between mitigating student stress and meeting the demands for academic rigour, both to satisfy student demands and achieve the recognition of professional, statutory and regulatory bodies that is critical to the career paths of many students (JISC, 2020b).

Recent research has also explored the relationship between students' performance and preferences when using online and offline assessments and how to improve digital assessment practice and student motivation and engagement (Abrar \& Mumtaz, 2017; Chase et al, 2017). Attitudes to assessment in open and distance learning environments have also been explored (Hatzipanagos 2009), since experience of appropriate assessment, good teaching, clear goals and standards, good materials and good tutoring are all 
positively associated with increased attainment for distance learning students (Ertl et al., 2008).

In addition, the shift to online assignment and employing online invigilation and/or proctoring systems has generated debates on academic integrity. The issue of academic integrity comes up frequently in discussion (Farrell, 2020), highlighting good practice that involves creative design of authentic assessment, moderation of marking, text matching software, clear guidelines to students about expectations around referencing and the use of mechanisms e.g. vivas to verify student academic work.

\section{Context}

University of London worldwide students are distributed across over 180 countries, studying with the university at a distance, but generally attending local Examination centres when taking paper based, fixed time examinations. Following a significant and rapid response to the impact of Covid-19 on the University of London Worldwide students' ability to participate in scheduled exams at a local Examination centre during the summer of 2020, the University provided over 100,000 exam opportunities online to approx. 35,000 students. Amrane-Cooper (2020) has described the background to this large scale transformation to assessment at the University of London.

The university made changes in assessment methods/formats due to the pandemic. The paper discusses a project that collected data about three final assessment routes students have taken: (a) Online, open-book exams with a paper to be downloaded and returned within a prescribed time, (b) Online exams via a Virtual Learning Environment (VLE), and (c) Digitally proctored exams. The aim was to generate understanding of this transition to online assessment, primarily from the perspective of the experience of the students who have been affected.

After explaining the background to this large scale transformation to assessment at the University of London, in the following section, we explore how we are evaluating and assessing the experience for students, staff and the institutional systems.

\section{Methodology}

\section{Aims and objectives}

This project aimed to collect data about and generate understanding of this transition to online assessment, primarily from the perspective of the experience of the students who have been affected. The project aimed to answer a fundamental question: What was the impact of the transition to online assessment on the experience of students and student outcomes? 
The objectives and associated target deliverables of the project were to:

- Evaluate the number of students who deferred or withdrew from examinations rather than engage with online modes of assessment;

- Assess the impact (if any) on grades and outcomes in the academic year 2019/2020, in comparison to student outcomes in 2017/2018 and 2018/2019;

- Investigate the rationale for establishing new forms of assessment and why these particular forms have been chosen by selecting 10 Academic Programmes and examining views of Programme Directors (PDs) on the original choices made and exploring PD perspectives on the quality of what was achieved;

- Explore the key factors that influenced choices at the University by interviewing three key UoLW colleagues;

- Analyse the views of responders, gathered by an online survey;

- Explore issues arising from survey results by interviewing 30-40 students;

- Gather further information if available through other media and institutional data, such as the Student Learning.

\section{Areas under investigation}

We are looking at four key areas (Figure 1):

- Student Behaviours;

- Student sentiment;

- Student outcomes;

- Operational issues.
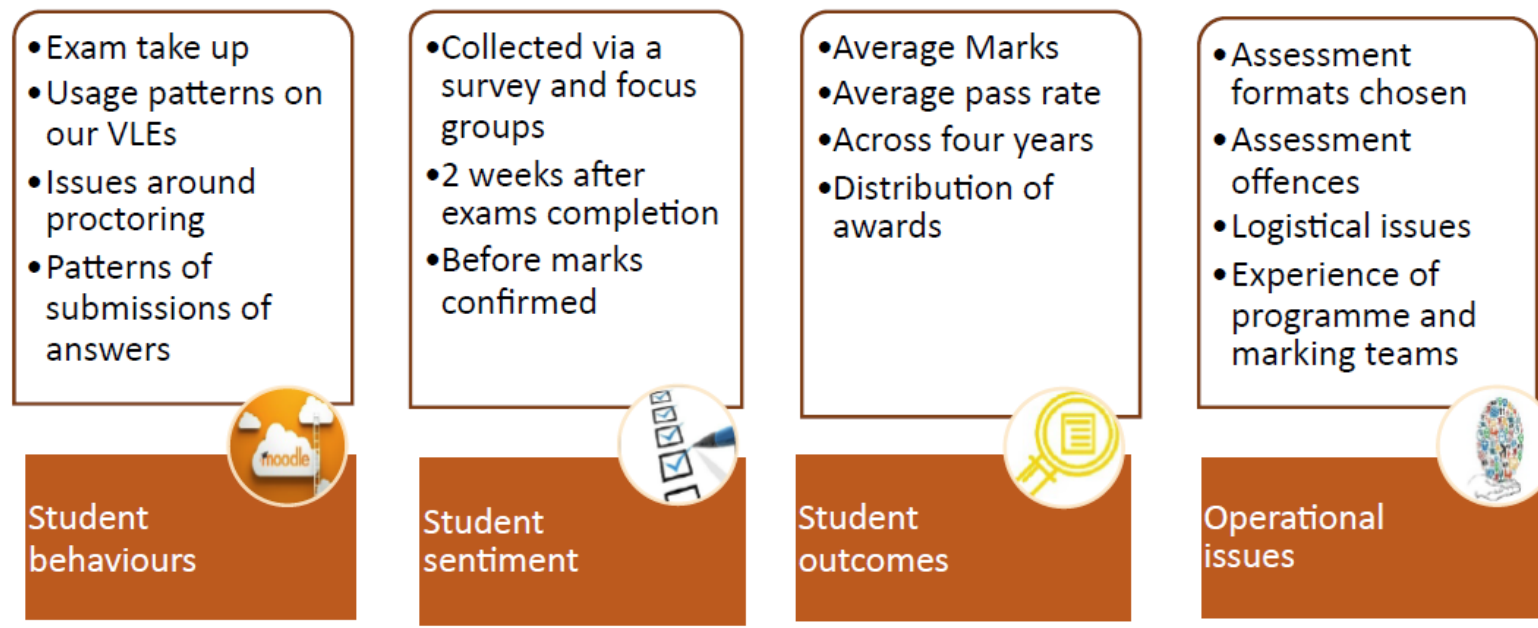

Figure 1. VLE usage patterns during exam period

The following section describes our preliminary findings. 


\section{Transitioning examinations online: findings}

\section{Uptake}

With exams completed, and while we are still processing the final data it appears that approximately $93 \%$ percent of our students were able to participate in online assessment. On average this is a higher percentage of exam engagement than in our traditional model of unseen exams taken at the University's 600 Examinations centres across the Globe. It appears that students felt they were given the opportunity to demonstrate their learning despite the pandemic. The assessments were selected from undergraduate and postgraduate academic subjects across a range of disciplines where online examinations took place. Findings reveal that students felt that there were benefits in moving to online assessment.

\section{Academic integrity and online assessment}

The data were examined and analysed, including parameters such as the location of the student (students are located geographically in over 20 time-zones). This would help to understand if local network and bandwidth availability or lack of had a significant impact on access and outcomes. The intention was also to examine differences in the format of examinations - we used three overall types of online examination: proctored exams, fixed time unseen closed book style exams and unseen but open book exams with a longer response time ( 24 hours or several days). Gender, age, programme of study and declared special needs that would require special examination arrangements are further parameters we have been exploring to ensure that no student is disadvantaged because of the move to online assessment,.

Student behaviour data are easily accessible via the institution's virtual learning environments (VLE) and in addition to a string uptake of online exams, we have also identified some initial findings. For example, with open book type exams, students still predominately accessed their exam paper as soon as their zonal exam became live for their location (the university operates zonal exam papers for our larger programmes to accommodate the need for security of the exam papers across global time zones). Some of the students appeared to submit within a few hours of receiving the paper, not taking the opportunity of a longer time-frame to evaluate the quality of their answers and reflect on their work. This has implications for how we help students prepare for future assessment, e.g. supporting them to develop strategies for a format that includes open book type assessment.

As the examiners completed their marking online, rather than marking paper exam scripts couriered to them, we also had the opportunity to explore the experience of academic staff 
in this "new normal". Exam boards have been meeting to confirm marks and awards. This will give us the opportunity to embark on a detailed analysis of student outcomes, comparing average marks and pass rates with previous years' performances. Examination formats may be an important factor to consider in the analysis of outcomes for students. Gender might be an important factor, if child care demands and work in the house under lockdown is disproportionately impacting on women students.

\section{Student voice}

Early response to the student experience survey has been strong, with a completion rate of $30 \%$ and over 8500 surveys to review. At this stage we are seeing students acknowledging and embracing the need to move to online assessment this year, and a strong correlation between VLE data in the survey responses give 93\% completing online assessment. There were also responses from students who did not complete all or some of their online exams, and this reveals that for this early sample, their lack of engagement with the assessment is generally Covid-19 related rather than having to do with issues of access to WiFi or suitable computer equipment. It appears that Illness, disruption and mental health issues resulting from the pandemic has meant these students were not able to engage with the assessment.

Feedback form the survey has helped to illustrate how communication with students worked best, how they undertook their assessment - by writing or by typing, and if they encountered issues uploading their answers to the VLE. These are all areas that map against the operational and logistical lessons learned that are being reviewing. And which will be essential for us in exploring our future assessment modes.

\section{Preference for the future}

In the final part of the student experience survey, we looked at the future and asked students if they would like online assessment practices to continue. Data collected so far indicate a strong agreement with this, with only $12 \%$ of respondents disagreeing. When presented with a range of possible future approaches to assessment including online assessment taken (a) at home or in an exam centre, or (b) paper based exams in an examination centre, there is an opportunity to understand which approach they would like to see in future assessment during their studies.

\section{Conclusions and further work}

The project collected data about three final assessment routes students have taken. The aim was to generate understanding of this transition to online assessment, from the perspective of the experience of the students who have been affected. 
The project data indicate that the transition to online assessment has facilitated changes in approaches to assessment, including the increased use of online exams. The adoption also touched on designing authentic assessments that use digital tools and require digital information literacies that are relevant to the professional lives of students.

We expect to have completed this large study by the end of October 2020 and look forward to sharing our findings with the sector as well as using it to inform our developments in assessment over the coming year. Moving 100,000 examinations online has implications for assessment practice and how much it improves student motivation and engagement, authenticity and validity considerations are obeyed in assessment design, how practice is set up to address the needs of students in distance learning and campus based environments and how the higher education sector keeps abreast of societal developments.

\section{References}

Abrar H., \& Mumtaz I. (2017). Finding the Relationship between Students' Performance and Preferences Using Online and Offline Assessments. International Journal of Scientific \& Engineering Research, 8(1), 363. ISSN 2229-5518

Amrane-Cooper, L. (2020, May 21). Putting 110,000 examinations online. University of London [Blog post]. Retrieved from https://london.ac.uk/news-and-opinion/centredistance-education/putting-110000-examinations-online

Chase, A., Ross, B., \& Robbie, D. (2017). Improving Digital Assessment Practice: A Case Study of a Cross-Institutional Initiative. Journal of University Teaching \& Learning Practice, 14(2). Retrieved from http://ro.uow.edu.au/jutlp/vol14/iss2/5

Emerge Education and JISC (2020). From fixes to foresight: JISC and Emerge Education insights for universities and startups, Report.

Ertl, H., Hayward, G., Wright, S., Edwards, A., Lunt, I., Mills, D., \& Yu, K. (2008). The student learning experience in higher education: Literature review report for the Higher Education Academy.

Farrell, O. (2020). Out of intense complexities, intense simplicities emerge. Assessment and the pivot online. Presentation at EDEN NAP Webinar.

JISC. (2020a). The future of assessment: five principles, five targets for 2025. Retrieved from http://jisc.ac.uk/reports/thefuture-of-assessment

JISC. (2020b). Learning and teaching reimagined: Change and challenge for students, staff and leaders, Report: July 2020.

Pauli, M., Iosad, A., \& Attewell, S. (2020) Assessment rebooted. Jisc / Emerge Education. Retrieved from http://jisc.ac.uk/reports/assessment-rebooted 